\title{
SAÚDE: UM DEVER DO ESTADO OU UM ASSUNTO DE FAMÍLIA? ANÁLISE DA EXPERIÊNCIA DE FAMÍLIAS DE UM BAIRRO POPULAR JUNTO AO SISTEMA DE SAÚDE
}

\author{
HEALTH: A DUTY OF THE STATE OR A FAMILY MATTER? ANALYSIS OF AN \\ EXPERIENCE OF FAMILIES FROM A POPULAR NEIGHBOURHOOD REGARDING \\ THE HEALTH SYSTEM
}

Ana Cecília de S. Bastos*

Zilma L. S. Velame**

Anamélia L. S. Franco ${ }^{* * *}$

Ana Emília Teixeira****

\begin{abstract}
Bastos ACdS, Velame ZLS, Franco ALS, Teixeira AE. Saúde: um dever do Estado ou um assunto de família? Análise da experiência de famílias de um bairro popular junto ao sistema de saúde. Rev Bras Crescimento Desenvolv Hum. 2006;16(2):01-15.
\end{abstract}

\begin{abstract}
Resumo: De que forma uma família utiliza os recursos de que dispõe no enfrentamento de circunstâncias relacionadas ao processo saúde-doença? A literatura sugere que o indivíduo submetido a condições adversas usa várias alternativas de superação de agravos: esgotando competências individuais, adota alternativas envolvendo uma rede de apoio social leiga e em seguida a prescrições dos profissionais supostamente competentes. Foram analisadas descrições das formas de enfrentamento de eventos ligados à saúde e doença na vida cotidiana, reconstituindo-se assim a experiência da família ao se relacionar com o sistema profissional de saúde. Os resultados sugerem: (a) a presença de um padrão de comportamentos e idéias gerenciando o uso do sistema profissional de saúde; (b) a adoção de sistemas terapêuticos paralelos, na dependência de uma avaliação contínua dos resultados obtidos, sendo o sistema formal um dos últimos recursos escolhidos, exceto frente a problemas acidentais ou crônicos; (c) a adequação das prescrições médicas às reais condições de vida da família; (d) a re-significação do sofrimento que minore a angústia e propicie o agir; (e) a presença de conflitos na interface família-sistema de saúde, na medida em que estão envolvidos diferentes recursos e sistemas de crenças e práticas.
\end{abstract}

Palavras-chave: Práticas de cuidado à saúde. Sistemas terapêuticos. Família.

\section{INTRODUÇÃO}

O presente estudo analisa significados presentes na experiência de famílias de baixa renda junto ao sistema de saúde. Selecionou- se este foco específico a partir do levantamento de episódios descrevendo práticas de atenção à saúde no contexto doméstico, relatadas durante o primeiro ano do estudo original ${ }^{1} \mathrm{e}$ durante os quatro anos subseqüentes. Para dar

\footnotetext{
* Doutora em Psicologia/UnB. Docente do Departamento de Psicologia da UFBa. Pesquisadora Associada do ISC/UFBa. Pesquisadora do CNPq. Endereço: Rua Macapá, 461, Edf. Horto de Ondina, ap. 601. Ondina. Salvador, Ba. CEP: 40.170-150.E-mail: acecil@ufba.br

** Psicóloga, Especialista em Saúde Coletiva, UFBA.

*** Doutora em Saúde Coletiva, UFBA, Docente do Mestrado em Família e Sociedade Contemporânea, UCSAL.

**** Psicóloga do Projeto AXÉ, Bahia. Bolsista de Iniciação Científica, PIBIC/UFBA, durante a realização deste trabalho.
} 
conta do material então reunido, construiu-se um marco teórico dentro de um espaço transdisciplinar formado numa intersecção da Psicologia do Desenvolvimento, da Antropologia da Saúde e da Planificação e Gestão de sistemas de saúde. Nesta introdução, após abordar a relação família, desenvolvimento humano e saúde, analisa-se a natureza dos sistemas terapêuticos utilizados no âmbito da família.

\section{Família, Desenvolvimento Humano e Saúde}

A família, enquanto primeiro ambiente social do indivíduo, é um contexto privilegiado para o estudo de processos de desenvolvimento humano.

Classicamente, disciplinas como a antropologia e a sociologia vêm conferindo à família funções e tarefas, das quais as mais importantes e permanentes parecem ser a reprodução da espécie, a criação e a socialização dos filhos, a transmissão essencial do patrimônio cultural. Identificar tais constantes não implica, absolutamente, o endosso a qualquer concepção universalista, e por isso mesmo restrita, de família. A família não existe como uma abstração; pelo contrário, é plural tanto em seus membros como quanto às suas experiências. Em um mundo complexo, no qual se torna impossível ignorar a crescente interdependência entre as várias esferas do viver, alterações como a diminuição de tamanho da família, o acréscimo de pais solteiros, a maior complexidade da maioria dos tipos de família, as alterações na interface da família com o mundo do trabalho, a emergência de redes de apoio e as estruturas familiares múltiplas são fenômenos que requerem uma abordagem capaz de dar conta da articulação, convergências e tensões de múltiplos papéis em diferentes esferas da vida social ${ }^{3}$. Do ponto de vista da saúde pública, é importante reconhecer a família como um sujeito capaz de propor estratégias, como defende Saraceno ${ }^{4}$. Nesse sentido, ao produzir e reproduzir práticas sociais, a família contribui simultaneamente para a permanência e para a inovação da cultura.

Novamente aí, ocorre heterogeneidade: as famílias ocupam espaços diferenciados em sua luta pela sobrevivência e pela reprodução da vida. A família é, também, o locus privilegiado para observar o impacto, a natureza e a atuação das redes de apoio social imediatas ao indivíduo, capazes, em graus diversos, de minimizar os efeitos de estressores na saúde, em diferentes pontos do ciclo de vida ${ }^{5,6}$.

Enquanto contexto de desenvolvimento humano, a família define-se como o nicho dentro do qual a cultura coletiva torna-se interligada com o desenvolvimento individual da criança7 . A trajetória de uma família, estruturada sobre práticas coletivas com funções de sobrevivência, é construída, portanto, num contexto amplo em relação ao qual se recorta o significado das idéias parentais que se colocam como um dos organizadores da inserção da criança no mundo social.

O uso do conceito de prática cultural remete à necessidade de articular diferentes níveis de análise: o individual e o social. Nesse sentido, seria uma idéia mais abrangente do que um comportamento ou atividade isolada, na medida em que se define prática cultural incluindo as características propostas por Goodnow ${ }^{8}$ : é vista como “natural” e fortemente regulada por contingências de aprovação social; é acompanhada por idéias sobre padrões de participação tidos como apropriados à condição de membro do grupo social em questão; é originária de uma história de aprendizagem e desenvolvimento, possuindo assim valor de sobrevivência para o grupo social como um todo.

A organização e funcionamento da vida cotidiana de uma família são, assim, produzidos por práticas culturais que envolvem processos de coordenação de diferentes subjetividades pessoalmente construídas ${ }^{7}$, dentro de um contexto marcado pela heterogeneidade. Desses 
processos dependem, em última análise, a própria sobrevivência da família como grupo social e a qualidade de vida de seus membros. É nesse sentido que a saúde torna-se um "assunto de família”.

As práticas de cuidado à saúde observadas em uma família articulam vários níveis de ação: a família, os serviços de saúde, o contexto social mais amplo onde estão integradas e os indivíduos, particularizados em suas ações. São práticas que refletem o contexto social e, ao mesmo tempo, estão implicadas no processo de construir subjetividades.

Tradicionalmente, observa-se que estudos que abordam a problemática de cuidado à saúde, tendo nos serviços o seu eixo principal, enfatizam políticas públicas de atenção à saúde no que diz respeito a diretrizes políticas, organização de serviços, implantação e implementação de ações em saúde. Parecem escassos, no entanto, estudos cuja ênfase incida na atenção no âmbito familiar, colocando à mostra decisões subjetivas do cuidado à saúde e as dinâmicas familiares onde elas se processam. Esta pode ser uma direção para se pensar possíveis dificuldades quanto à adesão da população a ações de educação e controle em saúde; como observa Massé ${ }^{9}$, a saúde pública, no mundo ocidental, não se mostrou ainda capaz de responder ao desafio crucial contemporâneo de propor programas de intervenção “culturalmente sensíveis e adaptados ao contexto no qual vivem as populações às quais são destinados”, especialmente quando se trata de populações vivendo em condições de pobreza e desigualdade social.

Assim como representa permanência e mudança, o contexto familiar significa simultaneamente risco e proteção para o desenvolvimento humano e a saúde. A dinâmica familiar de vidas interdependentes acarreta tanto a disponibilidade de suporte social como limitações: são os benefícios e custos dos vínculos sociais, na expressão de Elder Jr. ${ }^{10}$. Ao lidar com problemas de saúde, a família desenvolve mecanismos próprios de enfrentamento, certamente com os meios construídos em sua trajetória, e variando de acordo com os valores prevalentes em seu grupo social de referência e com a oferta e disponibilidade de recursos sócio-sanitários ${ }^{11}$.

A atenção aos processos de enfrentamento do adoecimento construídos no âmbito da própria família requer um deslocamento da perspectiva da doença para a saúde, exigindo (a) uma priorização crescente à investigação de padrões de vulnerabilidade e resiliência frente a situações que configuram adversidade: pobreza, status minoritário, violência, conflitos intrafamiliares e sociais ${ }^{12,13}$ e (b) a eleição de situações, grupos e momentos de risco no curso de vida das famílias ${ }^{14,10}$.

Nesse sentido, a valorização das experiências singulares de indivíduos e famílias, numa diversidade de contextos sócio-culturais, é relevante para compreender a dinâmica da relação risco-proteção, tendo a qualidade de vida como perspectiva ${ }^{11}$, e focalizando bidirecionalmente as expressões da subjetividade no processo saúde-doença, o que implica em mostrar como as pessoas respondem ao contexto e modificam o contexto. A família seria o contexto privilegiado para a observação de como atuam as fontes de apoio mais imediatas ao indivíduo, podendo-se pensar, como Costa e Lopez ${ }^{5}$, em dois níveis de apoio social: formal (profissionais) e informal (familiares, vizinhos, amigos, conselheiros religiosos etc.), claramente implicadas na construção cotidiana de itinerários terapêuticos ${ }^{15}$.

No contexto familiar, é possível identificar diferentes itinerários terapêuticos, envolvendo a percepção sobre o problema de saúde, a eleição da ajuda, a adesão a uma determinada terapêutica, o processo de avaliação e de tomada de decisões em relação a esta terapêutica. $\mathrm{O}$ modo como se realiza esse processo, no enfrentamento de problemas de saúde, interage com o sistema de valores que regulamenta posições e 
papéis na família, considerando que estes acarretam diferentes direitos e obrigações ${ }^{4}$.

Itinerários terapêuticos, a concepção e a própria inserção da família em sistemas de suporte social são, portanto, expressos, socializados e transmitidos no espaço doméstico.

A literatura sugere que o indivíduo submetido a condições adversas usa várias alternativas de superação de agravos que atingem sua saúde: esgotando competências individuais, adota alternativas envolvendo uma rede de apoio social leiga ${ }^{5}$. Não obtendo sucesso, recorre a prescrições dos profissionais supostamente competentes. Competências, tomadas como uma qualificação de níveis de desempenho do indivíduo, estariam presentes tanto antes de se recorrer aos profissionais, como também no momento de seguir as prescrições.

Tratar a família como contexto de desenvolvimento humano e como espaço privilegiado do processo saúde-doença implica, portanto, no plano da investigação, em assumir instâncias de análise que focalizem sistematicamente o próprio ambiente, trazendo exigências conceituais e metodológicas: o indivíduo-em-contexto, construindo novidade sócio-psicológica na atividade conjunta com outros. As práticas coletivas em curso no espaço da vida cotidiana da família são, ao mesmo tempo, produzidas dentro de um determinando contexto de disponibilidades e circunscritores (constraints). Portanto, os modos de perceber e lidar com uma doença passariam a fazer parte da organização da família, num esforço mútuo e partilhado. A experiência da família, vista ela própria como um sistema em desenvolvimento, conduz à adoção ou abandono de práticas de cuidado, dando lugar à construção de modos pessoais de construção de itinerários terapêuticos, na busca de resoluções dos problemas de saúde-doença.

\section{Os sistemas terapêuticos e a família}

O sistema médico está interligado com os demais sistemas dentro de uma sociedade e partilha com estes as mesmas suposições, valores e visão de mundo ${ }^{16}$. Nas sociedades modernas, há um número considerável de grupos e indivíduos que oferecem ao enfermo sua maneira particular de explicar, diagnosticar e tratar as doenças ${ }^{17}$. Esses sistemas terapêuticos coexistem em paralelo, mesmo quando originários de diferentes contextos culturais. Helman ${ }^{17}$ supõe que, na maioria das vezes, o que importa para o doente é a eficácia de uma terapêutica em aliviar o sofrimento.

É no campo leigo, não-profissional e nãoespecializado da sociedade que, segundo Klein$\operatorname{man}^{15}$, as doenças são, em primeiro lugar, reconhecidas e definidas, para depois serem iniciadas as atividades de tratamento. Helman ${ }^{17}$, assinalando o lugar privilegiado ocupado pelo grupo doméstico na atenção à saúde, estima que 70\% a $90 \%$ dos tratamentos de saúde ocorrem na família. A família é a sede primeira da assistência à saúde em qualquer sociedade, sendo as mulheres, geralmente as mães ou as avós, quem diagnostica as doenças mais comuns, tratando-as com os recursos que tiverem à disposição. O itinerário terapêutico só incluiria novas alternativas fora do âmbito doméstico uma vez esgotada essa competência básica. Essas novas alternativas, de início, seriam, preferencialmente, a auto-medicação, orientações de amigos e familiares, recurso a religiosos ou grupos de auto-ajuda, especialmente a alguém, leigo, com experiência específica naquele tipo de problema. O auto-tratamento é baseado em crenças leigas sobre a estrutura e o funcionamento do corpo, e a origem e a natureza das doenças. Tais crenças incluem diversas substâncias e tratamentos, tais como medicamentos industrializados, remédios tradicionais, “ $\mathrm{di}$ cas", além de mudanças na dieta e no comportamento ${ }^{16}$.

Alguns estudos voltados para a avaliação da qualidade dos serviços de saúde tangenciam a questão dos modelos de crenças envolvidos nas práticas de atenção à saúde. No 
entanto, escalas e questionários utilizados por programas de avaliação têm sido criticados por sua inadequação cultural, uma vez que não passam de traduções de modelos americanos e europeus, sem esforços consistentes para adaptar os instrumentos às realidades locais ${ }^{18,19}$. Além disso, reduz-se a experiência do usuário no sistema de saúde a uma pergunta dicotômica relacionada a satisfação ou insatisfação, sem contemplar considerações sobre as crenças, os modos de vida, as concepções do processo saúde-doença dos usuários do sistema de saúde, aspectos que claramente influenciam os modos de utilização dos serviços pelo usuário.

Williams ${ }^{19}$ considera que a geração de mudanças relevantes na prestação de serviços necessita de melhores descrições das crenças, das opiniões e dos possíveis modos de viabilização para o sistema de saúde, devendo ser implementadas estratégias metodológicas que permitam aos usuários expressarem-se em seus próprios termos.

Nessa perspectiva, têm sido desenvolvidos alguns estudos utilizando enfoques de inspiração etnográfica e/ou mudando o foco de interesse para avaliar o sistema de saúde do ponto de vista do usuário. Atkinson ${ }^{18}$, ao tratar da qualidade dos serviços de pré-natal oferecidos por uma maternidade-escola de Fortaleza, entrevistou as mulheres usuárias dos serviços e os profissionais, analisando as expectativas das usuárias, a organização do serviço, o aconselhamento, o aprimoramento técnico e as relações interpessoais. Na análise, foram confrontados os dois conjuntos de avaliações: leigas versus profissionais, evidenciando-se conflitos sugestivos de diferenças nos modelos explanatórios em que cada grupo se baseia.

Gattinara, Ibacache, Puente, Giaconi e Caprara ${ }^{20}$ desenvolveram um estudo na Bolívia para analisar a qualidade da consulta ambulatorial, no que se refere à relação entre os profissionais e os pacientes. Constataram a presença de atitudes discriminatórias com relação aos usuários provenientes de estratos sócioeconômicos mais baixos. Entre os problemas de comunicação analisados, incluíam-se a percepção de incapacidade diagnóstica e terapêutica pelo usuário e a incapacidade dos serviços públicos de reconhecer as especificidades interculturais da região. Stallard e Lenton ${ }^{21}$ investigaram o nível de satisfação dos pais de crianças portadoras de paralisia cerebral, considerando a adequabilidade do apoio dado à família, a conveniência das consultas, a prestação de informação sobre a condição da criança. A insatisfação expressou-se quanto ao tipo e qualidade da informação prestada pelos profissionais. Trad, Bastos, Santana e Nunes ${ }^{22}$ privilegiam uma perspectiva etnográfica, ressaltando as diferentes lógicas envolvidas na avaliação de serviços de saúde feita por profissionais e por usuários. Faz-se necessário, portanto, sensibilizar os profissionais para, ao atuar nos vários níveis de prevenção e reabilitação em saúde, perceber especificidades culturais das comunidades usuárias.

A relação entre saber médico e senso comum, nas práticas e representações de saúde e doença, originam-se de uma re-interpretação, por parte dos membros das classes populares, de um jargão médico que eles não compreenderiam ${ }^{23}$. Deve-se questionar a natureza desta "não compreensão"; é possível que ocorra uma apropriação e uma utilização do saber médico, entretanto modificadas pela utilização dos recursos disponíveis na realidade do sujeito.

Em seu estudo, Bastos ${ }^{1}$ descreveu alguns mecanismos culturalmente estruturados pelos quais a criança participa, crescentemente, da vida familiar, tornando-se um membro co-responsável ao partilhar afazeres, preocupações e decisões, e ao desenvolver atividades ligadas à sobrevivência, à organização da vida cotidiana, à produção e consumo de bens, e a projetos familiares coletivos. A partir do vasto material qualitativo reunido nesse estudo, fez-se um novo recorte, focalizando práticas e crenças sobre 
saúde no cotidiano dessas famílias. Partiu-se da observação inicial de um estado de “desamparo instituído” das famílias, as quais, em seu dia a dia, abdicam de sua cidadania, desacreditando do Estado como instância que represente qualquer garantia quanto a seus direitos mais fundamentais. As alternativas de ação diante de problemas, quase sempre, baseavam-se na sorte ou destino, ou em regras de reciprocidade ao nível do suporte social informal disponível (família, vizinhança, amigos).

Diante disso, formulou-se um conjunto de questões. Como pensar a saúde no contexto de famílias de camada popular urbana, particularizadas em sua experiência dentro de um contexto sócio-cultural? Como essas famílias utilizam os recursos sócio-sanitários de que dispõem no enfrentamento de circunstâncias relacionadas ao processo saúde-doença? Como focalizar essa realidade a partir de uma visão sistêmica, capaz de dar conta das interdependências entre os indivíduos e os contextos nos quais eles se desenvolvem - e que são, também, instâncias dinâmicas, em desenvolvimento?

O objetivo do presente estudo é analisar os significados presentes na experiência cotidiana de famílias de um bairro popular de Salvador, enquanto usuárias do sistema profissional de saúde, a partir da descrição de práticas de cuidado à saúde e das crenças nelas presentes, sintetizando a experiência de diferentes gerações. Focaliza-se, especificamente, o relato que a família faz sobre o modo como enfrenta problemas de saúde e se utiliza dos recursos disponíveis ao nível dos serviços de saúde, em torno de um foco principal, que é a atenção à saúde da criança.

\section{MÉTODO}

Este trabalho define-se como um estudo de casos, realizado como seguimento ao estudo de Bastos ${ }^{1}$, quando foram estudadas dez famílias, oriundas de cinco contextos familiares básicos: a família extensiva, a família nuclear com muitos filhos, a família nuclear com poucos filhos, a família matrifocal e a família com nova união. É importante destacar que as famílias estudadas aqui não são usuárias do Programa de Saúde da Família.

Essas famílias foram visitadas em suas residências, durante um período de cinco anos. No primeiro ano, o contato foi intensivo, realizado semanalmente; no follow up, as visitas foram mais espaçadas, realizando-se a cada três meses no ano 2 e 3, e mensalmente nos anos 4 e 5. Nesses dois últimos anos, as visitas tiveram simultaneamente um caráter de pesquisa e intervenção, priorizando-se a atenção à saúde como foco das entrevistas. No contato com as famílias, eram adotados recursos variados (entrevistas, principalmente, mas também observação, fotografia e videotape), produzindo-se um material qualitativo rico e diversificado. Cada família participante assinou um termo expressando seu consentimento informado para participar do estudo.

Para a análise dos dados, foram inicialmente retomadas as transcrições originais das entrevistas realizadas no estudo original, com as dez famílias, e as observações registradas em diários de campo, destacando-se os episódios temáticos contendo relatos de práticas de cuidado à saúde, bem como crenças nelas envolvidas. Foram incluídas práticas utilizando recursos formais, dentro do sistema de saúde público e privado, e recursos informais, baseados na própria família ou no suporte social informal dentro da comunidade, selecionando-se um leque de episódios que descrevem o cuidado a pessoas doentes, no presente ou na história da família, hábitos de higiene, avaliações do atendimento dos médicos e outros profissionais de saúde, condições sanitárias do ambiente, nível e fonte de informação sobre saúde. Esse levantamento resultou numa edição do conjunto de episódios relativos à saúde observados no total 
de famílias estudadas, privilegiando-se então aqueles em que a família efetivamente recorre aos sistemas profissional e institucional de atenção à saúde.

\section{RESULTADOS E DISCUSSÃO}

Os resultados descrevem modos através dos quais as famílias utilizam o sistema profissional de saúde: circunstâncias, crenças e sistemas de avaliação relacionados a esse uso. Destacam-se o uso diferenciado conforme o lugar do doente na família (mãe, criança ou outros parentes), a convivência entre diferentes sistemas terapêuticos, a representação do profissional de saúde, a medicalização do comportamento desviante. Discute-se ainda o impacto dos cuidados à saúde sobre o cotidiano da família.

\section{Quando usar o sistema profissional de saúde}

Uma primeira observação é que a decisão de procurar o serviço de saúde é mais freqüente em situações percebidas como de maior gravidade, o que não é o caso, por exemplo, de gripes ou distúrbios gastro-intestinais. A busca de cuidados médicos e hospitalares ocorre apenas quando não há mais recursos em casa e em último caso ou em complicações após cuidados domésticos, ministrados pela mulher mais velha mas envolvendo também outros membros da família.

D.Dilza, a matriarca de uma família do tipo extensivo, buscou o Sistema Formal de Saúde apenas duas vezes: a primeira, ao passar mal após um parto feito em casa, e a outra, quando nasceu sua filha mais nova. Normalmente, quando alguém adoece na família, D.Dilza conta com a ajuda dos filhos, principalmente em relação aos problemas mais graves e não cotidianos, como se vê em seu relato sobre procurar uma maternidade ao sentir-se mal estando grávida:

...conto com meus filhos mesmo. $\mathrm{Na}$ época, né, ela já estava bem crescidinha, a mais velha. Eu acho que não tinha tido ela [T] ainda. A mais velha estava quase mocinha, ela sempre foi ativa... Mas eu não fiquei internada nem nada, né? Na época, lá no Rio Vermelho (Cristina foi com a senhora?) Eu fui só, Cristina eu acho que estava com o irmão dela, o que é de junto dela, tava pequenininho ele ainda. ... É, e eu aí, eles me medicaram e eu vim m'embora...".

Depois, foi uma crise hipertensiva que a levou ao Serviço Médico. D.Dilza refere-se à doença como algo que depende do ambiente e procura ficar atenta à dieta prescrita por médicos e pela idéia de que é muito difícil melhorar o seu estado de saúde, depois que uma médica lhe disse que a preocupação causava o aumento da pressão:

A doutora tirou minha tensão, disse que eu, minha tensão estava de 18/9 ou 18/12. Ela até me passou um remédio, eu falei que ia tomar, disse assim 'a senhora escreve aqui para não me esquecer, para eu me lembrar em casa'. 'Não senhora, não vou escrever não porque a senhora vai ficar olhando aí e vai ficar aumentando mais sua pressão.'

Cabe à mulher cuidar das doenças mais comuns que acometem a família, receitando chás e fazendo recomendações para cada tipo de enfermidade, baseadas nas experiências vividas.

(...) doença é uma coisa muito difícil, é uma coisa que não gosta da gente. Graças a Deus. Tenho cinco filhos, esses meninos, nunca tive que sair assim tarde da noite de carreira. Aqui eu só saí duas vezes de noite pra ir pra maternidade.... Mas Deus me ajudou e tudo bem na hora apareceu um motorista que nos levou até o caminho e do caminho pra lá pegamos outro transporte. E assim, graças a Deus, ninguém aqui fica doente não. Uma besteirinha assim, uma dor de cabeça, isso não é doença. Uma gripezinha. (Dilza). 
Este fato coloca a mãe, cuidadora da família, numa posição que ela considera privilegiada, de ser também alvo de cuidados. O relacionamento da família com o sistema de saúde varia também, portanto, conforme o lugar do doente na família.

Já na família de Maria Lúcia, ir ao médico não parece se constituir um evento tão disruptivo. Ela solicita com freqüência o Sistema Formal de Saúde, não apenas no caso da doença crônica de sua filha, que tem um quadro alérgico raro e severo, ictiose lamelar congênita, mas também em relação aos problemas que surgem com as outras crianças. É possível que a continuidade no atendimento exigida pelas constantes crises da filha aumente a probabilidade de atenção mais ou menos regular aos problemas dos outros filhos, que tendem a ser medicalizados, mesmo quando não necessário. Essa prática permitiu que fossem identificados problemas sérios que esses outros filhos tinham: o mais velho, por exemplo, apresentou problemas cardíacos devido a infecção por beta-hemolítico, devendo se submeter a uma cirurgia. Quanto ao segundo filho, Maria Lúcia faz freqüentes queixas quanto ao seu comportamento: hiperatividade, agressividade; tende, da mesma forma que Lourdes, a explicar esse comportamento excessivo através de causas orgânicas. Esse filho, Lucas, já foi levado várias vezes ao neurologista, tendo porém um péssimo atendimento (prescrição de medicamentos anticonvulsivantes sem qualquer exame, clínico ou de outro tipo).

Considere-se ainda que o adoecimento, enquanto um evento disruptivo e inesperado, leva a família a fazer uma série de sacrifícios, que vão desde sair muito cedo de casa (muitas vezes sem se alimentar), deslocar-se para outros bairros, até faltar ao trabalho ou mexer no orçamento, tudo em busca de um atendimento mais especializado que favoreça a cura. É o caso de Lourdes, que aplica enxofre puro à filha, Patrícia, para tratar a escabiose que esta apresenta- va, atribuindo a responsabilidade por esse ato à médica que as tratou com descaso e indelicadeza: 'ela tem sarna! Fique longe de mim!'. Lourdes, que já estava aflita com o adoecimento em si, relata ter ficado muito perturbada com essa atitude da médica. Patrícia, desde pequena (7 anos), assumia já parte significativa dos afazeres domésticos. Com o adoecimento de Patrícia, portanto, Lourdes viu-se desamparada, sobrecarregada de trabalho, agravado por mais o de ter de cuidar da filha: Não sabia se trabalhava, se eu ficava em casa. Fiquei maluca. Ocorre uma mudança brusca na rotina familiar, acompanhada da idéia de que a doença é um peso a mais de trabalho (o doente é improdutivo).

Lourdes resiste em ir ao médico quando é ela própria quem apresenta problemas; afirma só procurar uma assistência médica em “último caso" e não parece desejar mudar esta situação. Para filhos ou outros parentes, ela mostra-se disposta a fazer sacrifícios para ir ao médico.

Também Maria Lúcia sacrifica-se em cuidar da saúde de seus filhos, buscando orientação médica, principalmente em relação a sua filha que possui uma doença crônica, mas quando se trata de suas freqüentes enxaquecas, recorre ao uso habitual de um determinado analgésico.

Ainda nesta categoria, na família de Aparecida, a hipertensão aparece como um caso de doença crônica, configurada como uma "doença de fato”. Ela tem hipertensão e constantes queixas de dores de cabeça, referindo-se várias vezes a este sintoma. Por conta deste problema e do tratamento constante que ele requeria na época da pesquisa, Aparecida se utilizava do recurso de deixar de trabalhar. Para ela, a atividade de ir ao médico impossibilitava uma boa freqüência ao emprego, optando por ser diarista, ficando assim com um horário mais flexível. Não se considera sem condições de trabalhar, em termos de bem-estar e força, e sim 
por ter que sempre faltar ao trabalho para ir ao médico e continuar o tratamento.

Nos episódios acima, está implícito que cuidar da saúde parece ser um assunto particular da família, que não deve interferir com o mundo do trabalho e apenas excepcionalmente envolve outros atores. Existe um projeto em comum, que, em sua formulação mais sintética, se define pelo reconhecimento que os pais esperam dos filhos, enquanto única esperança de amparo concreto na velhice. É isso que lhes diz a experiência. O lugar do Estado é, visto de dentro da família, uma incógnita; se dele vem, fortuitamente e quase como por sorte, um benefício ou outro, não se pode contar efetivamente com esse Grande Pai para assuntos de vida e morte.

\section{A convivência entre diferentes sistemas terapêuticos.}

Mesmo em se tratando de uma doença considerada grave e crônica como a epilepsia, o itinerário terapêutico adotado pela família inclui a busca e o uso simultâneo de vários recursos. Assim Lourdes se refere à tia portadora de epilepsia: Foi a tudo o que é lugar, sem que haja cura . . pra ficar boa mesmo só Deus.

Apesar de levar ao médico, em última instância só Deus pode dar um jeito na doença. Nota-se aí a importância da religiosidade, que aparece num momento de impotência frente ao problema. Deus aparece como o provedor da vida e da saúde; o sistema de saúde pode eventualmente dar maior conforto e diminuir o sofrimento imediato.

Além disso, o ficar doente é visto como algo que faz parte da vida e em particular da condição de ser pobre, que acarretaria uma predisposição para dificuldade, dureza, tragédia: ...e tudo isso acontece na vida do pobre, né? E se tiver que passar, o que se há de fazer? (Lourdes).
Sem condições, por estar doente, a tia ainda trabalha, por não ter outras pessoas para fazer os seus serviços; nota-se aí uma diferenciação entre a importância dada ao trabalho e a suas condições de saúde.

A epilepsia ainda é vista como uma entidade, algo que vem de fora do sujeito e exerce sua influência sobre o sujeito: ...Ela vem e ataca...acaba com ela.... No entanto esta é uma idéia que convive em paralelo com uma outra que a relativiza: Ela só cai se parar o remédio...

Surgem duas idéias oriundas de referências culturais a diferentes sistemas terapêuticos que convivem lado a lado. Um exemplo aplicado neste caso é a crença de que só Deus pode curar e ao mesmo tempo a busca de melhores médicos e recursos em "São Paulo”, evidenciando a assimilação simultânea do saber médico, do senso comum e das tradições familiares.

Lourdes também exemplifica como deixar uma crença em favor de um suposto saber médico, modificando assim seu comportamento frente ao doente, reduzindo o temor às crises de epilepsia: O médico disse que não pega.

Essa convivência de diferentes sistemas terapêuticos também surge claramente em outras famílias. Na família de Maria Lúcia, o saber médico é aplicado, mesmo em situações de automedicação observadas em suas freqüentes enxaquecas, ao preferir a medicação em gotas e não sob a forma de comprimidos:

... melhora mais rápido, né? (...) esse médico um dia me falou que esses remédios líquido... faz efeito mais rápido, né?

Um episódio que ocorreu com Lourdes ilustra o uso do Sistema formal de Saúde aliado às crenças religiosas, onde a ambos credita-se o mesmo valor:

Sei lá o que foi . . . Porque quando eu tive ela [Paula], com oito dias eu tive hemorragia. Aí voltei pro hospital de novo. Aí cheguei fiz uma promessa com Nossa Senhora de Lourdes, se eu ficasse boa, ela com 
um ano de idade, eu aí me vestia toda de branco, eu e ela, aí botava meu nome numa fita branca e largava lá e tirava o retrato. Só me restou este. O dela, tem um na igreja, outro tá com minha mãe, outro tá tudo esfarrapado...

Observa-se uma crença nas promessas que curam doenças, no entanto não se dispensa a intervenção médica e os cuidados hospitalares. Todo um ritual é cumprido para se adquirir a graça da cura por meio da promessa.

\section{A representação do profissional de saúde}

Na família de Lourdes, a epilepsia é doença considerada grave e sem perspectivas de cura para essa família. Sua tia sofre dessa doença há vinte anos, o que modificou o cotidiano das mulheres na família extensa, que funciona como um apoio.

Este fato é muito interessante porque Lourdes afirma com veemência em várias ocasiões que não gosta de médicos, que só procura um em último caso: Não gosto de médico, não gosto mesmo. Eu tenho RAIVA de médico.

Quando sua filha mais velha apareceu com uma espécie de sarna em seu corpo, Lourdes utilizou uma série de recursos caseiros e ensinados pelos vizinhos (o pessoal ensina eu dou a ela); como estes não surtiram efeito, a garota piorou. Lourdes vence suas resistências ( "Só vou pro médico na última hora”) e procura um atendimento num sistema público de saúde:

Sair 5 horas da manhã com uma pessoa doente, com fome, só com o dinheiro do transporte, pá chegar lá, a médica olhar pá cara da pessoa ainda sente nojo ainda?!. Então era pá a pessoa descarregar. Ela [a médica] nem chegou perto, só fez perguntar o que é que foi que eu dei, o que foi que eu não dei, como foi aquilo.

Demonstra seu ressentimento frente aos médicos, raiva, desejo de agressão uma certa desvalorização pessoal, pois, apesar de seus sacrifícios, encontra um atendimento marcado por uma atitude de descaso e nojo do profissional de saúde. Neste discurso percebe-se mais os conteúdos afetivos no uso do sistema formal do que um percurso das práticas empregadas. É uma elaboração a posteriori da situação vivida e que justifica sua ação atual de só procurar médicos quando os recursos caseiros esgotam.

Observa-se, também, o desconhecimento de que o relato dos sintomas ajuda no diagnóstico diferencial e a idéia de que o exame médico físico especifica a doença, atribuindo um saber que não é genuinamente profissional:

Leva os meninos, se ele não sabe o que é que as crianças tá sentindo, a função dele é examinar, mas não! (imitando a médica em tom de deboche) ' Tá sentindo o que?'

\section{A medicalização do comportamento desviante}

Lázaro é o segundo filho de Lourdes. Segundo esta, seus problemas começaram desde o seu nascimento. Considera que foi feliz até o nascimento de Lázaro. Quando Lázaro nasceu, o parto subiu pra cabeça.

Aqui, a experiência de Lourdes por ocasião do parto é identificada como um marco na configuração dos problemas posteriores ligados à pessoa de Lázaro, quando Lourdes faz uma transposição do seu problema na ocasião (o parto “subir para a cabeça”) para o seu filho, mantendo a mesma linha de significação, problemas na cabeça.

Lázaro, cujo nascimento marca a "infelicidade” de Lourdes com o marido, é visto por todos como o diferente, o doente, o preguiçoso: tem umas besteiras de arte aí, pinta uns quadros... Suspeitam de algum problema na cabeça (sic).

Não é valorizado pelo que faz (pintura, um tipo de escultura). Tem uma história de fra- 
casso escolar, mal sabendo escrever e ler. O próprio garoto se identifica e assume essa idéia: Tem um problema que [as coisas] não entra na cabeça. Fala de seu problema na $3^{\circ}$ pessoa e não na $1^{\circ}$ pessoa, como se ele não se colocasse como sujeito ativo de sua própria experiência. Atribui sua dificuldade na escola ao fato de ter um problema na cabeça, apesar de relatar não fazer os deveres de casa e de não ser estudioso. Parece emocionalmente instável, e os familiares nunca sabem o que esperar dele: apoio ou hostilidade. Lourdes sugere uma espécie de “castigo” como explicação para o seu modo de ser: é que ele nasceu no dia de Natal, e não lhe colocaram o nome de Natalício:

eu me arrependi da hora que não botei $<$ Natalício>, porque esse Lázaro não tem quem güente! O dia que ele amanhece "de calundu", minha filha, não tem quem possa!

A inconstância do humor de Lázaro e de seus comportamentos faz com que haja uma maior procupação e vigilância dos seus atos, em relação aos outros filhos:

Ele dá muito trabalho. (. . .) Do jeito que ele é gente pensa que. . . se ele beber ele vai fazer. . . alguma besteira.

A família não parece esperar que Lázaro faça na vida algo relevante, “que preste”; suas aptidões para arte não são consideradas como positivas e sim como mais um sinal de que ele não é normal. Visitando a família quatro anos após a conversa acima, soubemos que Lázaro estava casado com uma mulher mais velha, de modo a mais uma vez agir de acordo com o não esperado pela família, desagradando a mãe. Trabalha como pedreiro, mostrando se habilidoso, tal como esperado pela mãe há anos atrás. É sempre solicitado para algum serviço, e nunca deixa de conseguir um lugar para o pai. Agora, Raimundo vive na expectativa de "arrumar" trabalho com Lázaro - a quem tinha iniciado na vida profissional.

É interessante assinalar a percepção que a família tem do comportamento de
Lázaro não implicou em procurar um médico para fazer exames, embora se cogitasse disso, eventualmente. O que se observou a longo prazo foi que os principais recursos utilizados para a resolução dos problemas de Lázaro, ou pelo menos para sua integração no cotidiano, foram: (a) manter um tratamento diferenciado com Lázaro em relação ao restante da família, inclusive evitando aborrecê-lo ou mexer em suas coisas (Ninguém bole com ele porque se bulir tem até briga.) $e$ (b) a profissionalização o mais precocemente possível (entre 15 e 16 anos).

Observa-se que a família identifica uma diferença no comportamento de Lázaro, atribui uma causalidade (o parto ter subido à cabeça de Lourdes), uma conseqüência (a infelicidade conjugal da mãe). Afirma a não possibilidade de melhorar a situação e cogita da medicalização do comportamento socialmente desviante, ao esperar no sistema formal de saúde uma explicação satisfatória e uma possível melhora de seu estado. Vale ressaltar que aqui se trata de um problema de saúde na esfera mental, mas a forma de visão dessa família é organicista: busca-se um exame no corpo e uma resposta médica oficial.

Outro exemplo é o da família de D. Rosa, que narra uma história recorrente de alcoolismo: o marido e dois dos filhos. Um terceiro filho usa outras drogas, tendo ido embora para São Paulo devido a esse problema.

Rosa vive indignada com “as crises” que a família enfrenta por causa do alcoolismo de sua filha Vilma. Já fez várias tentativas de recorrer ao Serviço médico, mas Vilma rejeita qualquer forma de ajuda, negando sua dependência.

...eu acho que ela precisa de um psiquiatra. Foi um dia que deu um trabalho danado, saiu, bebeu....ela quando bebe fica louca, louca.(Rosa)

Vilma queixa-se da situação vivida pelo irmão que está deprimido, bebendo bastante e 
muito infeliz. Diz ter conseguido uma indicação para levá-lo ao CETAD ${ }^{+}$, mas o interessante é que o tratamento foi indicado para ela. É ela quem leva o irmão, conversa com psicólogos e se mostra bem comprometida em ajudá-lo, porém em momento algum admite a sua necessidade. Comenta ter gostado do local, “...tem psicólogos, médicos. É legalzinho o lugar. Você conhece?" e acrescenta dizendo que o irmão tem "se dado" bem.

"....ele tem se dado bem com três consultas ele já está melhor. Na primeira consulta ele ficou duas horas conversando, as pessoas são interessadas...”

Já na família de Seu Luís e D. Dilza, a tendência à medicalização é relativizada.

A família formada pelo casal Sr. Luís e D. Dilza é um arranjo do tipo extensivo. Na ocasião da coleta ele ficou desempregado, dizendo ter se aposentado e adquirido o privilégio de viver todos os dias como "domingos...todo dia pra mim agora é domingo... Dilza foi trabalhar hoje, sou eu que estou na cozinha.

D.Dilza cobra dele que faça biscates, ao que ele resiste. Parece que depois de um desses “domingos” de sua nova vida, Sr.Luís bebeu demais e no dia seguinte passou mal e teve um problema cardíaco que a família não soube explicar claramente. O médico recomendou the procurar um psicólogo; a equipe de pesquisa indicou o Serviço de Psicologia, mas ele não teve interesse, dizendo que não precisava, pois sabe se controlar a bebida: .porque, minha senhora, me diga: o que é que um psicólogo vai fazer?

Parece-lhe absolutamente estranho um profissional interferindo, de alguma forma, em um assunto de sua privacidade. A procura por auxílio para solucionar problemas de saúde só ocorre no momento da aflição, porque depois de sanadas as conseqüências da "dor", dificilmente busca-se tratar o sintoma.

\section{O impacto dos cuidados à saúde sobre o cotidiano da família}

Na organização do cotidiano familiar e na modificação da participação dos membros da família nesse cotidiano.

Um episódio, relatado por Patrícia mostra uma exigência e uma observação de como seus irmãos reagem frente a pessoas doentes na família, fazendo uma distinção quando é a própria mãe que adoece.

A gente conversa, mas eles nunca entendem nada, só quem entende mais sou eu e Lázaro. Os outros não entendem nada ainda. quer dizer, ela tá doente, sabe que tá doente, mas pra eles tá tudo bem..." Só quem pergunta as vezes é Paulo: 'Ela tá boa, mãinha?..." mas só Paulo, os menor... são desligados.

Isso muda quando se trata da própria mãe:

Quando mãinha tá sentindo alguma coisa, eles perguntam o que é que ela tem. Pedro não. Só Paulo, e Paula assim quando ela tá com vontade, às vezes ela pergunta. Mas quem pergunta mesmo é eu, Lázaro e Paulo.

Na família de Maria Lúcia, os meninos são frequentemente solicitados para ir à farmácia para comprar algum medicamento. Também Aparecida transmite a idéia de que a doença de algum membro da família deve modificar o nível de participação da criança no cotidiano da família, assim como ocorreu quando ela própria era criança.

"minha avó colocava eu pra lavar minhas calcinhas. Depois minha avó ficou doente também, eu fazia tudo, lavava prato (...) ajudava minha avó em casa, botava uma semana minha , outra de meu irmão de criação."

O adoecimento da avó aparece aí como o fator que provocou a inserção precoce das crianças em papéis que envolvem maiores aptidões e responsabilidades até então não demonstradas.

CETAD: órgão ligado à UFBA, responsável por assistência a usuários de drogas. 
Nesta categoria faz-se um elo com um dos modos de partilhar propostos por Bastos ${ }^{1}$ : eventos intra-familiares (originados pela dinâmica familiar), conflitivos ou não, requerendo algum tipo de tomada de decisões e gerenciamento, focalizando mais o interesse pelo outro que a competência em um determinado desempenho. Quanto ao cuidado à saúde ou ao interesse por pessoas doentes da própria família, observa-se uma exigência de participação, centrada na condição de pertencer à família, sendo identificados obrigações e papéis necessários à definição de um indivíduo como membro da família, independente da condição de ser criança. Não seria, pois, específico da criança enquanto ser em desenvolvimento, mas enquanto indivíduo que faz parte da família.

O acesso à assistência profissional e a qualidade da experiência ao transitar pelo sistema de saúde podem implicar numa nova forma de inserção social do indivíduo como cidadão.

Lourdes, até o nascimento de seu primeiro filho, não tinha sentido a necessidade de se identificar como cidadã, pois não tinha escola, trabalho ou casamento formalizados. O primeiro uso de um sistema formal feito por Lourdes foi o Sistema Médico Formal que propiciou o reconhecimento de sua existência diante do estado. É na contingência de seu primeiro parto que ela adquire, pela primeira vez, sua carteira de identidade: quando passa mal na rua, ela e seu marido são ajudados por um policial que questiona sobre seus documentos, enquanto a leva a um hospital. E por conta deste episódio Lourdes tira sua carteira de identidade e se torna cidadã para o mundo. Parece uma prática ainda comum no Brasil, entre as camadas mais pobres, as pessoas tirarem seus documentos em momentos marcantes, tais como nascimento, entrada na escola, num contrato trabalho, casamento civil ou religioso, falecimento.

Quando maltratada no âmbito desse mesmo sistema, como no episódio em que a médica atende mal sua filha que tem sarna, ela de- monstra o teor afetivo relacionado a se tornar cidadã reagindo com indignação frente ao sistema que lhe conferiu uma identidade, sem compreender por que esse mesmo sistema não pode servi-la e a sua família de forma digna e eficaz.

Também Dilza expressa sua mudança de atitude quando descobre que é um direito seu ter acesso a uma assistência de qualidade. Ela comenta como se desloca do papel de cuidadora na família para uma nova situação: eu agora posso ser cuidada também.

Observa-se, pois que a experiência junto aos serviços surge como oportunidade de exercício de cidadania, de exercício de direitos e deveres de cidadão. Esse aprendizado, de dimensões coletivas, envolvendo os diferentes sujeitos da saúde (profissionais e usuários), traz implicações importantes para repensar e otimizar práticas de educação para a saúde e para redimensionar a direção do cuidado quando é a família que se coloca como alvo e como sujeito estratégicos da atenção à saúde.

\section{CONCLUSÕES E PERSPECTIVAS}

Os resultados enfatizam alguns processos e características mais importantes da relação das famílias com o sistema de saúde formal, destacando-se: (a) a presença de um padrão próprio de comportamentos e idéias, moldado pela história de vida dos sujeitos e pelas características da situação de adoecimento, gerenciando o uso do sistema profissional de saúde; (b) a adoção de sistemas terapêuticos paralelos, na dependência de uma avaliação contínua dos resultados obtidos, sendo o sistema formal um dos últimos recursos escolhidos, exceto frente a problemas acidentais ou crônicos; (c) uma adequação das prescrições médicas às reais condições de vida da família, implicando modificações delimitadas pelas características e pela disponibilidade de recursos no ambiente doméstico; (d) a busca de explicações que justifiquem ao sujeito o porque de estar pas- 
sando por uma situação dolorosa, uma re-significação que minore a angústia e propicie o agir; e (e) a presença de conflitos na interface família-sistema de saúde, na medida em que estão envolvidos diferentes recursos e diferentes sistemas de crenças e práticas.

Tomando como exemplo o caso da família de Lourdes, vê-se que:

1. Há um padrão de comportamentos e de idéias que gerenciam o uso do sistema formal, baseados na história de vida singular dos sujeitos e nas características da situação de saúde: a escabiose, a epilepsia, o comportamento desviante medicalizado.

2. O itinerário terapêutico é baseado em crenças e atribuições de causalidade, avaliando-se qual a melhor forma de agir em cada situação, utilizando todos os recursos disponíveis, conforme aparece na terapêutica do familiar portador de epilepsia.

3. As pessoas buscam constantemente uma explicação, uma resposta que justifique ao sujeito o porquê de estar passando por uma situação dolorosa, de forma a re-significar essa situação e poder agir sobre ela. As significações que Lourdes associa aos seus partos demonstram particularmente essa vinculação.

4. O uso do sistema formal depende das experiências do sujeito frente ao atendimento recebido e da atribuição de uma competência para a resolução do seu problema. Caso alguma outra instituição - a família, os vizinhos, a religião apresente recursos para uma solução, dificilmente a pessoa se dirige ao sistema formal. Este, numa linha de ação, é colocado como uma das últimas alternativas de escolha. Vários dos episódios relatados (crises de epilepsia, tratamento da sarna) exemplificam esta assertiva.

5. Nos casos tomados como acidentais, em situações de emergência (o parto, por exemplo), o sistema formal de saúde recebe um outro valor, pois é o primeiro a ser solicitado. No entanto, esse recurso também é acompanhado, lado a lado, pelas normas familiares de cuidados e de crenças. Desta forma, mesmo acessando o profissional de saúde, a família busca adequar o tratamento às suas reais condições, visando uma execução e eficácia bem particularizada.

Em síntese: o adoecimento, como um fato presente na vida de qualquer ser humano, possibilita à família, núcleo social de contato mais direto, uma atuação natural como um sistema de "cura”, ao lado de mudanças tecnológicas que progressivamente estruturam modelos de assistência à saúde. Esta transição família - sistema de saúde revela-se uma área complexa, compreendendo características, funções diversas e muitas vezes aparentemente conflitantes, por envolver sistemas variados de crenças e passagem dos cuidados de uma instituição natural - a família, para uma formal - o sistema profissional de saúde.

\begin{abstract}
In what ways does an urban family use the resources it has to cope with circumstances related to the health-illness process? Literature suggests that an individual submitted to adverse conditions can use various alternatives to overcome hazards to his/her health. If $\mathrm{s} / \mathrm{he}$ is not competent to face the problem himself/herself, s/he adopts alternatives involving a lay network of social support. If those alternatives fail, s/he turns to prescriptions of competent professionals. The study focuses on descriptions of ways to cope with events linked with health and illness in daily life, rebuilding the experience of the family in its relationship to the health system. The results suggest: a) the presence of standard behaviors and ideas, shaped by characteristics of the illness situation, that are coordinated with the use of the professional health system; b) the adoption of parallel therapeutic systems, with a continuous evaluation of the given results, the formal system being one of the last chosen resources, except when the family faces accidents or chronic problems; c) the adequacy of medical prescriptions to the reality of family life; $d$ ) a re-signification of suffering that lessens the anguish and favors the action; e) the presence of conflicts in the family-health system interface, involving various resources and systems of beliefs and practices.
\end{abstract}


Key words: Health care practices. Therapeutic systems. Family.

\section{REFERÊNCIAS}

1. Bastos ACS. Modos de partilhar: a criança e o cotidiano da família. Taubaté: Cabral Editora Universitária; 2001.

2. Sarti CA. A família como espelho. São Paulo: Cortez; 2001.

3. Sarti CA. Famílias enredadas. In: Acosta AR, Vitale MAF, organizadores. Família: redes, laços e políticas públicas. São Paulo: Cortez:PUC-SP; 2005. p. 21-36.

4. Saraceno C. The concept of family strategy and its application to the family-work complex: some theoretical and methodological problems. In: Boh K, Sgretta G, Sussman MB. editors. Crosscultural perspectives on families, work and change. Binghamton (NY): Haworth Press; London: EUROSPAN-Haworth; 1989. p. 1-18.

5. Costa M, Lopez E. Salud comunitária. Barcelona: Martinez Roca; 1986.

6. Cicchelli-Pugeault C, Cicchelli V. Las teorías sociológicas de la familia. Buenos Aires: Nueva Visión; 1998.

7. Valsiner J. Niches of cultural embeddedness. In: Valsiner J. Comparative study of human cultural development. Madrid: Fundación Infancia y aprendizaje; 2001. p. 75-97.

8. Goodnow JJ. Differentiating among social contexts: by spatial features, forms of participation, and social contracts. In: Moen P, Elder Jr GH, Lüscher K, editors. Examining lives in context: perspectives on the ecology of human development. Washington (DC): American Psychological Association; 1995. p. 269-302.

9. Massé R. Culture et santé publique. Montréal: Gaëtan Morin; 1995.

10. Elder Jr GH. Family transitions, cycles and social change. In: Cowan P, Hetherington M, editors. Family transitions. Hillsdale (NJ): Lawrence Erlbaum; 2001. p. 31-57.

11. Bastos ACS, Trad LAB. A família enquanto contexto de desenvolvimento humano: implicações para a investigação em saúde. Ciênc Saúde Coletiva. 1998;2(3):106-15.
12. Coyne JC, Downey G. Social factors and psychopathology: stress, social support and coping processes. Annu Rev Psychol. 1991;42:401-25.

13. Luthar SS, Zigler E. Vulnerability and competence: a review of research on resilience in childhood. Am J Orthopsychiatric. 1991;61(1):6-22.

14. Cowan PA. Individual and family life transitions: a proposal for a new definition. In: Cowan PA, Hetherington EM, editors. Family transitions. Hilldale (NJ): Lawrence Erlbaum; 1991.p. 3-30.

15. Kleinman A. Concepts and a model for the comparison of medical systems as cultural systems. In: Currer C, Stacey M, editors. Concepts of health, illness and disease: a comparative perspective. Lexington: Berg; 1986. p. 29-47.

16. Ferreira J. O corpo sígnico. In: Alves PC, Minayo MCS, organizadores. Saúde e doença: um olhar antropológico. Rio de Janeiro: Fiocruz; 1994. p. 101-12.

17. Helman CG. Cultura, saúde e doença. Porto Alegre: Artes Médicas; 1994.

18. Atkinson SJ. Anthropology in research on the quality of health services. Cad Saúde Pública. 1993;9(3):283-99.

19. Williams B. Patient satisfaction: a valid concept? Soc Sci Med. 1994;38(4):509-16.

20. Gattinara BC, Ibacache J, Puente CT, Giaconi J, Caprara A. Percepción de la comunidad acerca de la calidad de los servicios de salud en los Distritos Norte e Ichilo, Bolivia. Cad Saúde Pública. 1995;11(3):425-38.

21. Stallard P, Lenton S. How satisfied are parents of pre-school children who have special needs with the services they have received?: a consumer survey. Child Care Health Dev. 1992;18(4):197-205.

22. Trad LAB, Bastos ACS, Santana EM, Nunes MO. Estudo etnográfico da satisfação do usuário do Programa de Saúde da Família (PSF) na Bahia. Ciênc Saúde Coletiva. 2002;7(3):581-89.

23. Boltanski L. As classes sociais e o corpo. $4^{\mathrm{a}}$ ed. Rio de Janeiro: Graal; 2004. 